\title{
Ärzte und Menschenrechte
}

Im September 1998 hat die Schweizerische Ärztezeitung anlässlich des 50. Jahrestages der Allgemeinen Erklärung der Menschenrechte der UNO zwei Schwerpunktnummern zu dieser Thematik herausgegeben. Dabei wurde unter anderem aufgezeigt, wie eng die ärztliche Tätigkeit mit der Frage der Menschenrechte verknüpft ist. In diesen Tagen wird uns bewusst, wie einschneidend dieser Zusammenhang für Kolleginnen und Kollegen sein kann. In den erwähnten Nummern der Schweizerischen Ärztezeitung hat Veli Lök, Professor der Orthopädie aus Izmir, einen Artikel über den medizinischen Nachweis der Folter publiziert. In diesen Tagen steht Prof. V. Lök vor Gericht. Ihm wird vorgeworfen, dass er seine Meinung zu Verhaftungen von drei Mitarbeitenden des türkischen Menschenrechtsvereins HRFT öffentlich kundgetan und damit das Gericht beeinflusst habe. Grund zu dieser Anklage ist ein Interview von Prof. Lök, in dem er die Vermutung äussert, die Verhaftungen im Anschluss an das Begräbnis eines Häftlings, der bei einem grossen Aufstand von Gefangenen im September 1999 ums Leben kam, hätten zum Ziel, seine Kollegen bezahlen zu lassen für die Aufdeckung der Folter und für die medizinische Behandlung der Überlebenden.

In einem weiteren Fall wurde ein Gynäkologe des Rehabilitations- und Behandlungszentrums in Izmir angeklagt, eine illegale politische Organisation zu unterstützen. Und dies allein deshalb, weil er in den letzten sechs Jahren weibliche Folteropfer untersucht und behandelt hat.

Diese Beispiele zeigen, wie sich das gesellschaftliche und politische Umfeld auf die ärztliche Tätigkeit auswirken und die hippokratische Tradition behindern kann. In dieser Situation ist die ärztliche Solidarität gefragt. Es soll deutlich werden, dass sich Ärzte und Ärztinnen in ihrem Einsatz für Menschenrechte gegenseitig stützen und Menschenrechtsverletzungen weltweit wahrgenommen und öffentlich gemacht werden. Dies ist eine wirksame Form der Prävention. Wir sind froh, dass der Zentralvorstand der FMH sich in dieser Richtung engagiert und seinen Einfluss in internationalen Gremien, insbesondere in der World Medical Association WMA, geltend macht.

Dr. med. Conrad Frey, Dr. theol. Hansjörg Vogel Therapiezentrum SRK für Folteropfer 